\title{
E-learning methodology in English language courses for employed adult learners in Slovakia
}

\author{
Valéria Medárová \\ School of Management / City University of Seattle, Bratislava, Slovakia, vmedarova@vsm.sk
}

\begin{abstract}
The paper analyses e-learning methodology in language education in the specific category of Slovak adult learners with work experience. The current labor market situation in Slovakia puts pressure on employees to develop their language skills, mainly in the English language. The research focuses on application of adaptive e-learning methodology for this specific learner category. A studied group of learners took part in a free pilot course of the English language for intermediate learners, which was designed as an on-line course in the learning management system Moodle. The outcomes of the pilot course and the following learner feedback showed many interesting learning tendencies and motivational backgrounds of adult language learners. The research has revealed various challenges of online language courses, such as high drop-out rate, lack of human contact, poor time management and others. In summary, if properly designed and managed, online language courses for adult learners have a great potential in career development.
\end{abstract}

Keywords: e-learning; language learning; course design; adult learner; employee education; Moodle

\section{Introduction}

E-learning in the workplace has great potential since development of the knowledge society is unimaginable without life-long learning. In Slovakia, employee training using e-learning technology is still not widespread or fully developed. This limitation is even more obvious in language learning with the use of e-learning technology and methodology.

The author of the paper analyzes conditions of effective employee training using elearning technologies and the most common obstacles that hinder the education process in the workplace. The area of the author's research is the possibility of effective introduction of e-learning in language education in the specific category of Slovak adult learners with full-time employment. This category of learners has been selected due to their specific learning needs and limitations. As fully-employed adults, they do not have easy access to language education in the traditional format of language courses. However, the current job market and the overall economic situation in Slovakia put pressure on Slovak employees to develop their language skills, mainly in the English language. The language learning system in Slovakia has still not sufficiently met those learning needs.

The research focuses on application of adaptive e-learning methodology for this specific learner category. The goal is to propose a set of efficient learning tools that can provide the right content to the right person at the right time.

\section{Methods}

We have developed an online English language course, which serves as a testing environment for various e-learning tools and linguistic methodologies. Participants of the course represented a sample group of Slovak adult learners with full-time employment or work experience. They had various career backgrounds and levels of experience with language learning. We observed their learning process, learning styles, frequency of study, study results, and other factors. The observed factors lead to the 
hypothesis that the right combination of computer technology and human element in teaching languages is justifiable and effective.

\section{Design of the Pilot Online Course of English for Intermediate Learners}

The pilot online course of English was created to verify effectiveness of various elearning tools and their adaptability to individual learner needs. It was conducted on the online learning portal Moodle, as an unofficial language course of the School of Management. The course was divided into 6 weeks - 6 modules. Each module contained a set of various learning activities focused on several language skills and language components, including grammar explanation, vocabulary on specific topics, reading passages, interactive listening activities, and video files. Grammar explanation files consisted of pdf files with explanation created by the course instructor, as well as video explanation of grammar elements and interactive grammar exercises available on various free online educational portals. Reading passages were selected from various available online and textbook sources. Vocabulary lists were either created by the course instructor or adopted from textbook sources. Listening exercises and video files with recorded real-life conversations were selected from several available language learning websites. Variety of learning tools is crucial. Using many methods of explanation that match learners' needs can solve the problem of low motivation and difficulties with understanding study topics (Melicheríková \& Bušíková, 2012).

To stimulate learners' interaction, we created a discussion activity in the form of online chat forum enabled by Moodle, where the contributors could give their opinions on topics of the week. Also, the learners had a possibility to practice their speaking skills in Skype interviews with the instructor once a week, during a 15-minute conversation, which was adjusted to individual speaking skills and vocabulary of each learner. Each week/module was concluded by a short online quiz/exercise designed by the course instructor. Every end-of-week test contained 20 grammar and vocabulary questions related to the topics of the previous week. It was possible to do each quiz 3 times, at any time before Week 6 of the course, giving a learner a chance to test his/her gained knowledge repeatedly.

Course participants were selected from a pool of interested people who took a simple grammar/vocabulary test for pre-intermediate learners. All the participants were adults, employed in various companies in Slovakia or having work experience in a company in Slovakia. The course was very open and user-friendly (the pilot course was completely for free), which means the learners could choose their pace and frequency of study - which activities they will do, how many times they will do them, and when they will do them. For example, a learner could choose to do all the activities for the given week in the proposed order or do only some of them in random order. Also, a learner could choose to be passive for several weeks and then catch up with the missed course material later on. This rather open and flexible approach to individual learning progress is justified by the belief of many researchers. For example, Sanchez-Villalon et al. (2010) state that learners should become developers of their own learning path, while tutors should act as their guides and help them develop their critical thinking. 


\section{Results and Discussion}

\section{Outcomes of the Pilot English Course}

The first pilot course of English in the online format was running in July - August 2014, with 15 participants. The second pilot course, with 20 participants, lasted from October to November 2014. The content, assignments, and schedule (distribution of learning activities within 6 week-modules) of both courses was exactly the same. In the first pilot course, 9 out of 15 participants completed the course and took the final online test. In the second course, 7 out of 20 participants completed the course, including the final test. The final test contained 50 multiple-choice questions related to vocabulary and grammar covered in the course. The questions were a selection and mix of questions taken from 6 previous end-of-week tests, which concluded each particular course module (course week). Individual grades for the final tests were calculated immediately after completion and they ranged from $60 \%$ to $98 \%$, the average grade being $87.0 \%$. We can consider it a high success rate.

The course participants used the possibility to select learning activities and do them repeatedly as they wished. Also, they took the chance to skip some of the activities if they did not feel they were interesting for them. For example, only a few learners participated in online discussions and only a limited number of them used the opportunity to conduct an interview with the instructor via Skype.

Also, some of the students did not follow through to the last $\left(6^{\text {th }}\right)$ week of the course and interrupted their study after a few weeks. The main reason, as stated in a learner feedback survey, was lack of time for study caused by work duties and various personal issues. The first pilot course was organized in the summer season; therefore, some of the participants could not finish it or complete all the activities due to their summer travel plans. Table 1 shows the drop-out rate of the participants during the 6-week course.

Table 1. Drop-out rate during two 6-week pilot courses.

\begin{tabular}{|c|c|c|}
\hline & $\begin{array}{c}\text { Remaining number } \\
\text { of active participants }\end{array}$ & $\begin{array}{c}\text { Remaining } \\
\text { active participants in \% }\end{array}$ \\
\hline after Week 1 & 26 & 74.2 \\
\hline after Week 2 & 23 & 65.7 \\
\hline after Week 3 & 21 & 60.0 \\
\hline after Week 4 & 20 & 57.1 \\
\hline after Week 5 & 19 & 54.2 \\
\hline
\end{tabular}

Despite these facts, we consider the number of participating students (16 out of 35 completed the course) and their final course results as success, taking into consideration the fact that the student sample was very varied and randomly chosen.

The purpose of end-of-week tests was to give learners an opportunity to practice grammar and vocabulary topics covered in the given week and, at the same time, to verify their acquired knowledge. In design of both end-of-week tests and the final (end- 
of-course) test, we used a test-design tool of the Moodle system, which automatically evaluates students' responses. The learners could take each end-of-week test repeatedly, up to 3 times, at any time during the course. Thus, they could "learn on their mistakes" and improve their test results. As Yousefzadeh (2010) states in analysis of computer-based feedback in language learning courses, the most beneficial feedback for language learners is feedback provided immediately, which is especially challenging in a big student group with various ability levels. In this aspect, learning management systems prove to be very efficient.

Table 2 shows actual participation rate in specific online activities of the course. The learners were mostly interested in grammar explanation, reading passages, and grammar exercises. In addition, many of the learners "clicked on" the relevant links more than once and went back to them if they found them very useful. On the other hand, class discussions and video links were the least popular in the observed group of learners. Low participation in discussion may be caused by lack of time or human factors, such as fear of making mistakes in English and "losing face" in front of other participants. Low interest in video links is rather surprising. We suppose one of the reasons could also be psychological - fear of not being able to follow "real life" conversation in the English language. Also, since the number of "clicks" on video files started dropping after Week 3, we can assume that the learners gradually lost interest in the topics of the recorded conversations.

Table 2. Participation in online course activities and assignments in two pilot courses.

\begin{tabular}{|l|c|}
\hline \multicolumn{1}{|c|}{ Activities and Assignments } & Participation of students in \% \\
\hline Reading Passages & 62.3 \\
\hline Vocabulary Lists & 57.7 \\
\hline Grammar Explanation & 67.6 \\
\hline Grammar Exercises & 58.0 \\
\hline Listening Activities & 55.2 \\
\hline Videos with Conversations & 36.1 \\
\hline Class Discussions & 25.2 \\
\hline End-of-week Tests & 40.0 \\
\hline End-of-course Test & 45.7 \\
\hline
\end{tabular}

\section{Learner Feedback on the Pilot English Course}

After each of the two pilot courses, we conducted a feedback survey in which the participants evaluated effectiveness of various learning tools and the overall quality of the course. The questions concerned individual types of activities related to: grammar explanation and exercises, reading passages, listening skills, comprehension of videos, 
vocabulary lists, online quizzes at the end of each module, online discussions, and Skype interviews. Most questions required response in the form of the Likert scale (from 1 to 5), while some were open questions, such as naming 3 most effective and 3 least effective learning activities.

We received 7 filled-out questionnaires from the participants of the first pilot course (the pool of 15 learners) and 8 responses (the pool of 25 learners) after the second course. In addition, we obtained comments in a form of e-mail reaction from 3 more course participants. As we expected, the responses reflected various personal learning styles, preferences, time constraints, work duties, and other limitations the learners were dealing with during the course. For example, when asked to choose 3 most effective and 3 least effective learning activities, the respondents gave overlapping answers, that is activities like videos and discussions were judged as productive by some learners and as unproductive by others. However, all the respondents agreed that the course contributed to improving their English speaking skills, and that Moodle portal is a suitable environment for a language course.

Most verbal comments on the pilot course were very positive:

"Some of the articles were interesting, bringing new information."

"I liked that I could test my knowledge in online quizzes."

"All the activities seemed very useful. We could practice everything because there were so many possibilities."

"I like discussions, where I could write my opinions."

"It was a demanding course, but I reviewed a lot of my knowledge and I learned a lot of new things... That was possible thanks to a variety of activities."

"One of the advantages was that I could study at home. I didn't need to go anywhere."

"I liked the fact that I was not limited by time. I could do the activities when I had time

- in the morning, in the afternoon, or late at night."

On the other hand, some negative comments referred to the following issues:

"Participation in online discussion was very low, and students' contributions were too short."

"A disadvantage was a missing contact with classmates. There was an online discussion forum where we could contribute, but the learners did not use it much."

"I didn't find videos with conversations very meaningful."

"I didn't have time to do the last two online quizzes while they were open, which is my fault... I am sorry there was no chance to do them later."

The final question in the survey focused on the preferred form of studying the English language. There were three choices:

1. in-class course with a teacher and classmates

2. individual (face-to-face) classes with a teacher

3. purely online course

4. online course with Skype interviews

5. online course combined with face-to-face consultations with a teacher (blended course) 
The responses varied here, too. Some respondents picked more than one choice. As a result, the most attractive choices proved to be the possibilities \# 4 (6 votes) and \# 5 (6 votes) - an online course with Skype interviews and a combination of online course and consultations with a teacher, followed by the possibility \# 1 - a traditional in-class course with a teacher and classmates (4 votes).

In summary, the survey of user satisfaction gave us an interesting picture of effectiveness of the applied e-learning tools. The learners appreciated the flexibility of the online study format as well as the opportunity to choose from a wide selection of learning tools and match them conveniently with their specific learning styles.

A significant number of survey respondents would welcome learning the English language in the online or blended format in the workplace. This research outcome proves a big potential of e-learning and adaptive learning methodology in foreign language education in Slovakia.

\section{Implications for e-learning in the Workplace in Slovakia}

Application of e-learning tools in education in Slovakia is not common practice in corporations and organizations. Therefore, e-learning has not fully fulfilled its potential yet. Small and medium-sized organizations all over the world face similar obstacles to implementation of effective e-learning programs in the workplace. Our research of this topic has led to realizing 4 main categories of barriers to implementation of e-learning in SMEs. These are: conceptual barriers, organizational barriers, technology, and the human factor. The conceptual barriers are related to definition of the purpose of elearning in the organization and its alignment with the organization's needs. The organizational barriers include planning, communication, funding, control and improvement, and application of skills. Technological barriers are related to quality, support, and update of information and communication technology (ICT) and communication media. Last but not least, individual and social factors play a significant role in application of e-learning in the organization (Medárová et al, 2012).

The learner feedback of the pilot online English courses showed the human factor as an even more significant issue or barrier to learning than we had expected. It was reflected in lack of time devoted to study and early drop-out rate (as shown in Table 1).

\section{Conclusions}

Based on the pilot course outcomes and feedback responses, we can conclude that the online format has a great potential and offers many promising opportunities for learning a foreign language, especially for working (and busy) adults. However, there still is a significant need of personal communication and contact with people, whether it takes places online or in real life.

Our study is limited by a small sample of learners and a relatively short period of observation of the learning process (the course took place two times). Further research is needed to clarify motivations and fears of adult learners as participants of online language courses.

Successful design and application of online language courses for working adults requires suitable criteria for selection of learners (pre-tests), appropriately designed 
course content (a balanced selection of various skill-oriented learning tasks and feasible amount of workload in a limited time - weekly modules), and more opportunities to provide individualized feedback to learners. Also, it is necessary to find ways to motivate adult learners to work consistently and avoid early drop-outs or interruption of study.

To sum up, there are still many challenges ahead of us if we want to improve the quality level and efficiency of e-learning in language education. In this effort, we should take into consideration a complex of linguistic, pedagogical, technical, organizational, and psychological factors, which can present both benefits and obstacles to online learning.

\section{References}

Medárová, V., Bureš, V., \& Otčenášková, T. (2012). A review of obstacles to successful e-learning deployment in SMEs. Journal of Innovation Management in Small \& Medium Enterprises, Vol. 2012, 9 pps. Available at http://www.ibimapublishing.com/journals/JIMSME/2012/715039/a715039.html

Melicheríková, Z. \& Bušíková, A. (2012). Adaptive e-learning - a tool to overcome disadvantages of e-learning. In Emerging eLearning Technologies \& Applications (ICETA), 10th International IEEE Conference. IEEE, Stará Lesná, 263-266. ISBN: 978-1-4673-5120-1.

Sanchez-Villalon, P.P., Ortega, M., \& Sanchez-Villalon, A. (2010). Multimedia integration for language e-learning: Content, context and the e-dossier. US-China Education Review, (7)8, 1-10.

Yousefzadeh, M. (2010). Computer-based feedback vs. instructor-provided feedback and second language learners' reading comprehension. International Journal of Instructional Technology and Distance Learning. (7)7. Available at: http://itdl.org/Journal/Jul_10/article03.htm 